\title{
Surface Investigation of Photo-Degraded Wood by Colour Monitoring, Infrared Spectroscopy, and Hyperspectral Imaging
}

\author{
Giorgia Agresti, ${ }^{1}$ Giuseppe Bonifazi, ${ }^{2}$ Luca Calienno, ${ }^{3}$ Giuseppe Capobianco, ${ }^{2}$ \\ Angela Lo Monaco, ${ }^{3}$ Claudia Pelosi, ${ }^{1}$ Rodolfo Picchio, ${ }^{3}$ and Silvia Serranti ${ }^{2}$ \\ ${ }^{1}$ Department of Cultural Heritage Sciences, University of Tuscia, Largo dell'Università, 01100 Viterbo, Italy \\ ${ }^{2}$ Department of Chemical Engineering Materials \& Environment, Sapienza-Rome University, Via Eudossiana 18, 00184 Rome, Italy \\ ${ }^{3}$ Department of Agriculture, Forests, Nature and Energy (DAFNE), University of Tuscia, Via San Camillo de Lellis, 01100 Viterbo, Italy \\ Correspondence should be addressed to Claudia Pelosi; pelosi@unitus.it
}

Received 30 May 2013; Revised 29 July 2013; Accepted 13 August 2013

Academic Editor: Luciano Bachmann

Copyright (C) 2013 Giorgia Agresti et al. This is an open access article distributed under the Creative Commons Attribution License, which permits unrestricted use, distribution, and reproduction in any medium, provided the original work is properly cited.

\begin{abstract}
The aim of this investigation is to study the changes occurring on the surface of poplar wood exposed to artificial irradiation in a Solar Box. Colour changes were monitored with a reflectance spectrophotometer. Surface chemical modifications were evaluated by measuring the infrared spectra. Hyperspectral imaging was also applied to study the surface wood changes in the visible-near infrared and the short wave infrared wavelength ranges. The data obtained from the different techniques were compared to find the possible correlations in order to evaluate the applicability of the Hyperspectral imaging to investigate wood modifications in a noninvasive modality. The study of colour changes showed an important variation due to photo-irradiation which is the greatest change occurring within the first 24 hours. Infrared spectroscopy revealed that lignin degrades mainly in the first 48 hours. Concerning Hyperspectral imaging, the spectral features in the visible-near infrared range are mainly linked to the spectral shape, whereas in the short wave infrared cellulose and lignin affect shape and reflectance levels. The proposed approach showed that a correlation can be established between colour variation and wood degradation in the visible-near infrared range; furthermore in the short wave infrared region surface chemical changes can be assessed.
\end{abstract}

\section{Introduction}

The focus of this work is to study the surface modifications of poplar (Populus spp.) wood by reflectance spectrophotometry, Fourier Transform Infrared (FT-IR) spectroscopy, and Hyper Spectral Imaging (HSI) in order to understand the mechanisms that cause the changes and to suggest possible solutions to avoid the degradation phenomena. The choice of poplar was due to its widespread use in Italy for the creation of statues, ceilings, furniture, doors, painted panels, and so forth.

In cultural heritage the monitoring of wood surfaces during light exposure should be performed through nondestructive methods to avoid the paradox of damaging a work of art while monitoring its preservation state $[1,2]$. For this reason colour measurements were chosen as a possible method to evaluate wood surface changes.
Since colour changes on wood surfaces are due to photo degradation of its chemical constituents, the study of the relationship between CIELAB colour changes and changes in chemical composition due to irradiation is of practical importance both in cultural heritage and in contemporary artefacts and objects [3].

This work starts from previous studies, developed by the same authors of this paper, regarding colour measurements on poplar and chestnut wood [4-7]. The novelty of this work, in respect of the previous ones, is the attempt to verify the possible correlations existing between colorimetric and chemical data in the perspective to develop simple, fast and reliable techniques to detect wood surface modifications.

The first studies dealing with the application, in the visible range, of multi spectral and HIS-based techniques to wood date back to 1941 [8] where this approach was used to identify compression wood in conifers, where compression wood appears more opaque in comparison with normal wood 
that appears translucent. Results showed some limitations. Methods based on near infrared (NIR) imaging were thus developed and applied to classify wood (i.e., compression and opaque) [9] and further "refined" to perform region mapping (i.e., bark, compression, and normal wood) [10]. In the recent years the utilisation of HIS-based techniques increased considerably, also in the field of wood studies where they are used especially to perform the chemical surface mapping for obtaining the distribution of lignin, galactose, and glucose in different wood species [11].

The focus of this work is to make a comparison between classical colorimetric investigation procedures, chemical analysis, and the proposed innovative HIS-based technique in order to verify the possibility to use colour measurements as a quick and simple method to control the surface modifications. The fulfillment of this goal was achieved by examining the correlations between classical colorimetric and chemical data with wood surface spectral characteristics detected in the (i) VIS-NIR (400-1000 nm) and (ii) SWIR (Short-Wave Infrared, 1000-2500 $\mathrm{nm}$ ) wavelength ranges. This approach is of great interest in the perspective to set up efficient, robust, noninvasive, and non-destructive analytical tools addressed to evaluate status and modifications of photo-degraded wood surfaces.

\section{Materials and Methods}

2.1. Sample Preparation. Wood samples were obtained by a single board of poplar. After cutting, the samples were stored in darkness in a conditioned room at $65 \%$ relative humidity and a temperature of $22^{\circ} \mathrm{C}$ to reach the $12 \%$ of moisture content. To perform the FT-IR analysis directly on wood surface, slices with a size of 10 (diameter) $\mathrm{mm}$ were obtained from the specimens of poplar. The dimensions of the slices were suitable for the FT-IR diffuse reflectance accessory. The same slices were used to perform the HSI measurements.

2.2. Accelerated Ageing. The accelerated ageing of the samples was performed in a Model 1500E Solar Box (Erichsen Instruments $\mathrm{GmbH} \& \mathrm{Co}$ ). The system is equipped with a $2.5 \mathrm{~kW}$ xenon-arc lamp and an UV filter that cuts off the spectrum at $280 \mathrm{~nm}$. The samples were exposed in the Solar Box chamber from 1 to $504 \mathrm{~h}$ at $550 \mathrm{~W} / \mathrm{m}^{2}, 55^{\circ} \mathrm{C}$, and the UV filter at $280 \mathrm{~nm}$. The experimental conditions were chosen following the specifications supplied by Erichsen, in order to simulate the sunlight exposition.

2.3. Colour Monitoring. After exposure for a given length of time the samples were removed from the Solar Box chamber, and the colour was measured using an X-Rite CA22 reflectance spectrophotometer. The characteristics of the colour measuring instrument are the following: colour scale $\mathrm{CIEL}^{*} a^{*} b^{*}$; illuminant D65; standard observer $10^{\circ}$; geometry of measurement $45^{\circ} / 0^{\circ}$; spectral range $400-700 \mathrm{~nm}$; spectral resolution $10 \mathrm{~nm}$; measurement diameter $4 \mathrm{~mm}$; white reference supplied with the instrument. The CIELAB colour system was used where $L^{*}$ describes the lightness while $a^{*}$ and $b^{*}$ describe the chromatic coordinates on the green-red and blue-yellow axes, respectively. The differences in lightness $\left(\Delta L^{*}\right)$, chromatic coordinates $\left(\Delta a^{*}\right.$ and $\left.\Delta b^{*}\right)$, and total colour $\left(\Delta E^{*}\right)$ were then calculated using these parameters according to Normal 14/93 (1993) and EN 15886 (2010). The total colour difference, $\Delta E^{*}$, between two measurements $\left(L_{1}^{*} a_{1}^{*} b_{1}^{*}\right.$ and $\left.L_{2}^{*} a_{2}^{*} b_{2}^{*}\right)$ is the geometrical distance between their positions in CIELAB colour space. It is calculated using the following equation: $\Delta E_{2,1}^{*}=\left[\left(\Delta L^{*}\right)^{2}+\left(\Delta a^{*}\right)^{2}+\left(\Delta b^{*}\right)^{2}\right]^{1 / 2}$.

Measurements were taken at the following hour intervals: $0,1,2,3,4,5,6,7,8,9,10,11,12,24,48,72,96,120,144,168$, $216,312,408$, and $504 \mathrm{~h}$.

To guarantee that successive measurements were made in the same area a graduated mask was used.

Ninety colour measuring points were chosen and three measures for each point were performed, according to Normal $14 / 83$, so that two hundred and seventy measurements were realized at each exposure time.

2.4. Fourier Transform Infrared Spectroscopy. Infrared spectra were obtained using a Nicolet Avatar 360 Fourier transform spectrometer. For each sample 128 scans were recorded in the 4000 to $400 \mathrm{~cm}^{-1}(2500-25000 \mathrm{~nm})$ spectral range in diffuse reflection modality (DRIFT) with a resolution of $4 \mathrm{~cm}^{-1}$. Spectral data were collected with OMNIC 8.0 (Thermo Electron Corporation) software.

To obtain the FT-IR spectra, sample slices were directly inserted in the FT-IR diffuse reflectance accessory unit. As background the spectrum of the $\mathrm{KBr}$ powder was used.

FT-IR spectra were recorded at the following time intervals: $0,6,12,24,48,72,96,120,144,168,216,312,408$, and 504 hours.

Peak heights were measured using OMNIC software according to the method described in the literature [12].

2.5. Hyperspectral Imaging. Hyperspectral analyses were carried out in two steps: a 1st step addressed to analyse the degraded wood surfaces in the wavelength interval 400$1000 \mathrm{~nm}$ (VIS-NIR) and a 2nd step in which the analysis was performed in the interval 1000-2500 nm (SWIR). The investigations were developed with two different sensing devices:

(i) ImSpector V10E (SPECIM Ltd, Finland) acting in the range $400-1000 \mathrm{~nm}$, with a spectral sampling/pixel of $2.8 \mathrm{~nm}$, a dispersion of $97.5 \mathrm{~nm} / \mathrm{mm}$, and $\mathrm{F} / 2.4$ numerical aperture, coupled with a CCD camera (780 $\times 580$ pixels). Pixel resolution was 12 bits;

(ii) Specim SISUChema XL, embedding an ImSpector N25E (Specim Ltd, Finland) acting in the range from 1000 to $2500 \mathrm{~nm}$, with a spectral sampling/pixel of $6.3 \mathrm{~nm}$, coupled with a MCT camera $(320 \times$ 240 pixels). Pixel resolution was 14 bits.

These two detection architectures were specifically set up in order to allow a static (off-line) and also a dynamic analysis, that is the possibility to carry out tests on "moving" samples. Both devices work as a push-broom type line scan camera allowing the acquisition of spectral information for 
each pixel in the line. The transmission diffraction grating and the optical components provide high light throughput, high-quality and distortion-less images. The result of the acquisition is constituted by a digital image where each column represents the discrete spectrum values of the corresponding element of the sensitive linear array. Both analytical stations are controlled by a PC unit equipped with specialised acquisition/preprocessing software, developed to handle the different units and the sensing device and to perform the acquisition and the collection of the spectra.

\subsection{Statistical and Spectral Analysis}

2.6.1. FT-IR and Colour Data. These data were analysed with the StatSoft Statistica 2010 advanced statistics software. As a first step, data distribution was plotted and visually checked for normality. Differences between treatments were checked with the standard paired $t$-test, with ANOVA and M-ANOVA analyses. Posthoc tests were conducted with Tukey HSD test method. Linear and nonlinear regression analyses were used to develop prediction models.

2.6.2. HSI: Spectra Acquisition and Handling. For the 1st set of acquisitions $(400-1000 \mathrm{~nm})$ the ImSpector V10E was installed on a Leica M205C stereomicroscope. The energizing source was constituted by MI-150 Dolan Jenner fiber optic device equipped with a dichroic lamp. For the 2nd set of acquisitions (1000-2500 nm) the SISUChema XL was used, equipped with macrolens allowing the acquisition of wood samples with a resolution of $30 \mu \mathrm{m} /$ pixel. Images were acquired through scanning each investigated sample line by line.

The calibration of the procedures was performed through recording black and white reference images. Certified standards were used. Black image $(B)$ was acquired to remove the dark current effect of the camera sensor. White reference image $(W)$ was acquired using a ceramic tile, calibrated with a NPL Spectralone specimen, in the same condition employed for the raw image acquisition. The image correction was thus performed adopting the following equation:

$$
I=\frac{I_{0}-B}{W-B} \times 100
$$

where $I$ is the corrected hyperspectral image in a unit of relative reflectance (\%), $I_{0}$ is the original hyperspectral image, $B$ is the black reference image ( $\sim \%$ reflectance), and $W$ is the white reference image ( $\sim 99.9 \%$ reflectance). All the corrected images were then used to perform the HIS-based analysis, that is to extract spectral information and to select the effective wavelengths for the final classification purposes.

Spectral data analysis was carried out adopting standard chemometric methods $[13,14]$, by the PLS_Toolbox (Version 6.5.1, Eigenvector Research, Inc.) running inside Matlab (Version 7.11.1, The Mathworks, Inc.). In particular, the spectra preprocessing was performed as follows: raw spectra were preliminary cut, at the beginning and at the end of the investigated wavelength range, in order to eliminate unwanted effects due to lighting/background noise. Concerning VIS-NIR, the wavelength reduction was from 121 to $81 \mathrm{~nm}$ so that the investigation was carried out in the spectral range $500-900 \mathrm{~nm}$. As regards SWIR, the reduction was from 256 to $240 \mathrm{~nm}$ resulting in a spectral range 1005-2500 nm. Different pretreatments, De-trend 1st polynomial, Mean-center, 1st Derivative, Standard Normal Variation, Generalized Least Square Weighting (GLSW), and Baseline techniques, were systematically used to classify the different investigated samples.

Principal Component Analysis (PCA) was applied to the spectral data for all investigated samples. It was used to decompose the "processed" spectral data into several principal components (PCs) (linear combinations of the original spectral data) embedding the spectral variations of each collected spectral data set. According to this approach, a reduced set of factors is produced. Such a set can be used for discrimination, since it provides an accurate description of the entire dataset. The first few PCs, resulting from PCA, are generally employed to analyse the common features among samples and their grouping: in fact, samples characterized by similar spectral signatures tend to aggregate in the score plot of the first two or three components. Spectra could be thus characterized either by the reflectance at each wavelength in the wavelength space, or by their score on each PC in the PC space. Samples characterized by similar spectra, which belong to the same class of products, are grouped in the same region of the score plot related to the first two or three PCs, whereas samples characterised by different spectral features will be clustered in other parts of this space.

Partial Least Squares Discriminant Analysis (PLS-DA) was used to find a model able to perform an optimal discrimination among classes of samples and to predict new images. PLS-DA is a supervised classification technique, requiring a prior knowledge of the data [15]. PLS-DA is used to classify samples into predefined groups by forming discriminant functions from input variables (wavelengths) to yield a new set of transformed values that provides a more accurate discrimination than any single variable (wavelength). A discriminant function is then built using samples with known groups to be employed later to classify samples with unknown group set. Therefore, once the model is obtained, it can be applied to an entire hypercube and for the classification of new hypercubes. The result of PLS-DA, applied to the hyperspectral images, is a "prediction map," where the class of each pixel can be identified using colour mapping.

\section{Results and Discussion}

3.1. Colour Changes of Wood Samples. Colour variability of poplar wood was widely discussed elsewhere suggesting the necessity to perform a high number of measurements in order to avoid this variability $[4,16]$. In particular, 270 colour measurements were obtained at each exposure time. M-ANOVA and Tukey tests were applied to the chromatic coordinates as function of irradiation times, until 504 hours of exposure (Table 1). ANOVA test underlines that $L^{*}, a^{*}$, and $b^{*}$ undergo statistically significant changes after the exposure times. Tukey's Honestly Significant Different (HSD) test is 


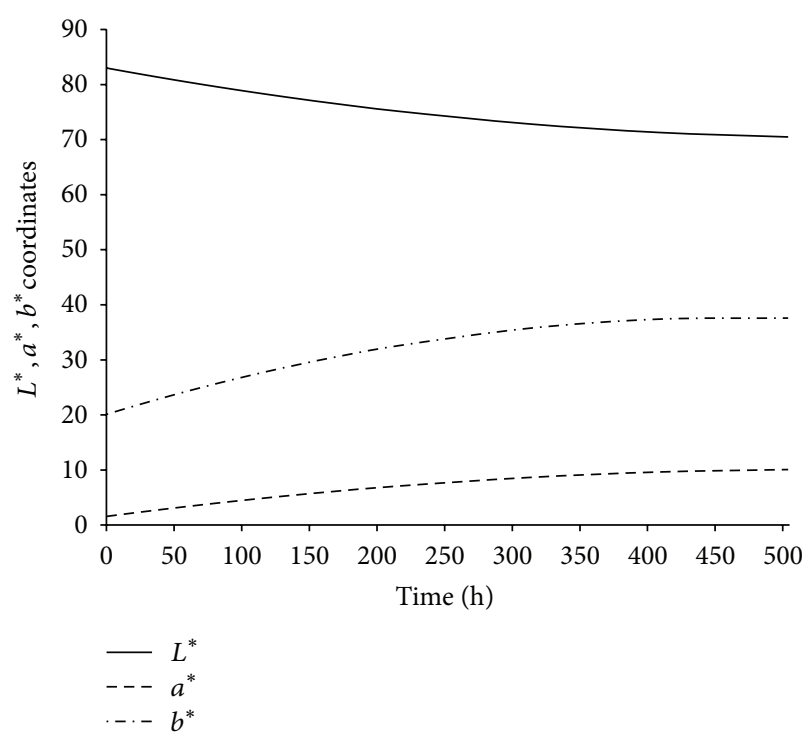

Figure 1: Colour changes of poplar samples due to photoirradiation. Variation of $L^{*}, a^{*}$, and $b^{*}$ parameters at different exposure times as calculated from the regression analysis shown in Table 2.

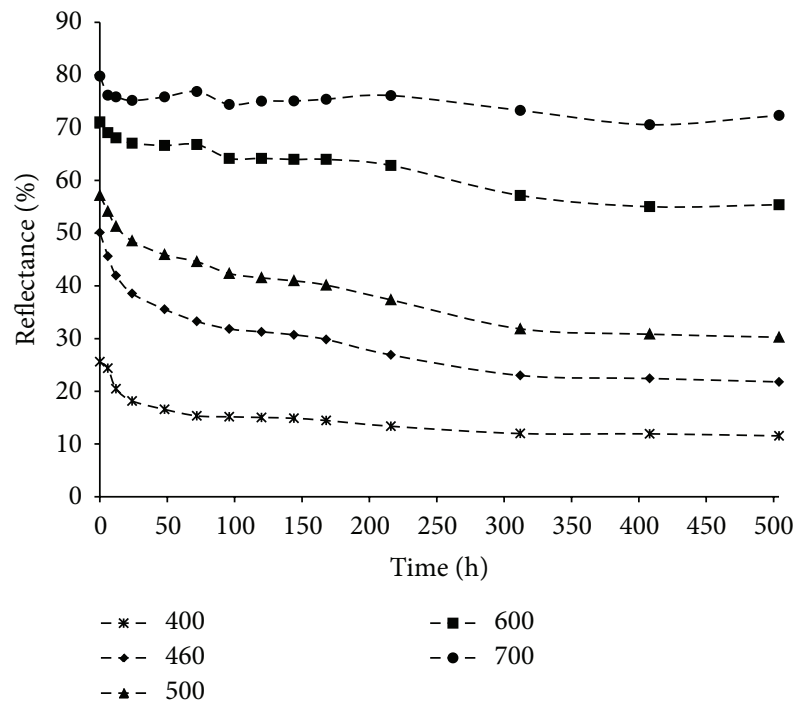

FIGURE 2: Variation in the reflectance spectra of poplar wood due to photo irradiation. Focus on the changes occurring at specific wavelengths within $504 \mathrm{~h}$.

used in conjunction with the ANOVA in order to find the means significantly different from each other. The letters a, b, $c$, and so forth in Table 1 (columns HSD) indicate the means' groups statistically different. In particular, Table 1 puts in evidence that during the first hours of irradiation there are low differences suggesting the possibility to start the measurements directly after 6 hours of irradiation.

As the chromatic coordinates undergo statistically significant differences at the chosen irradiation times, the nonlinear regression analysis was applied to the coordinates at different hours of exposure in Solar Box in order to evaluate the

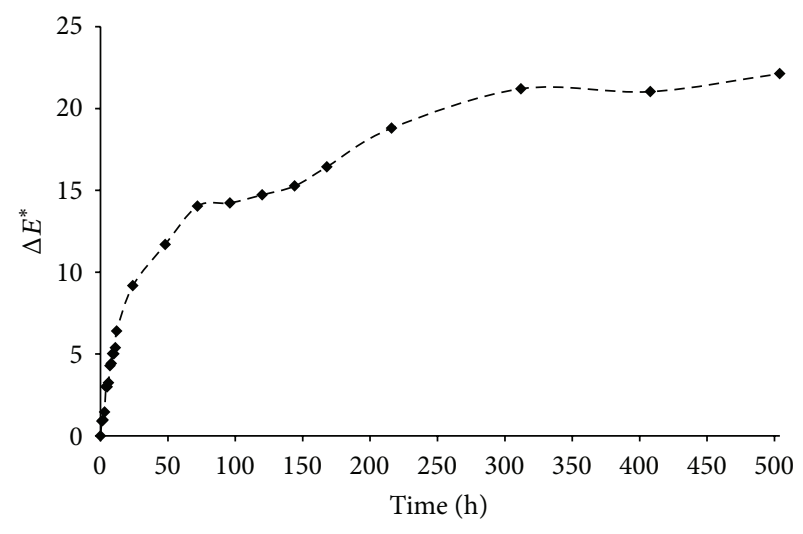

FIgURE 3: Changes in $\Delta E^{*}$ values due to exposure in Solar Box of the poplar samples over $504 \mathrm{~h}$.

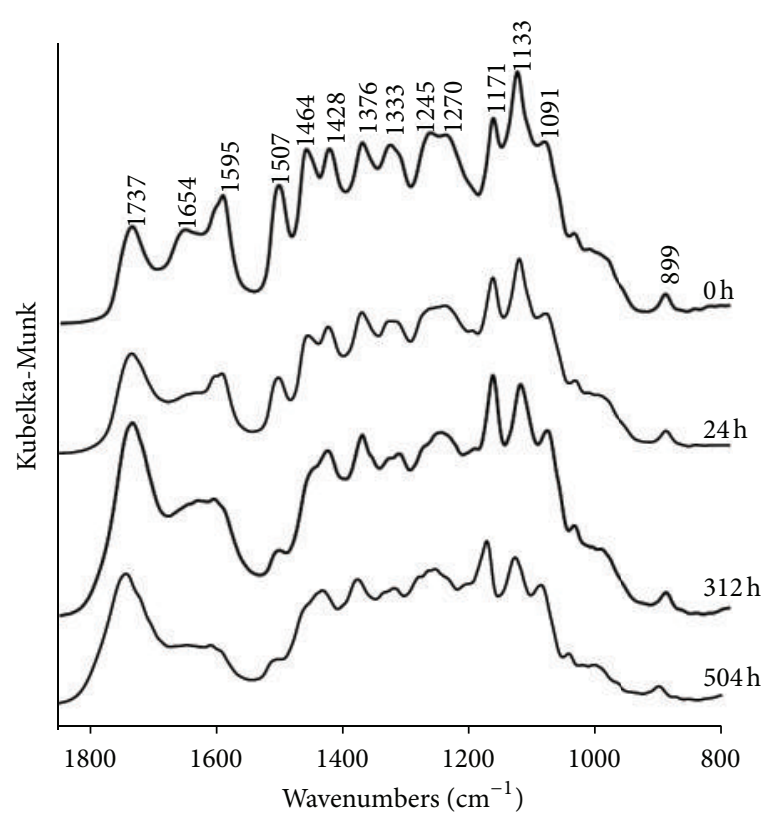

FIGURE 4: Diffuse reflectance spectra of poplar slices measured at chosen exposure times. Focus on the region $1850-800 \mathrm{~cm}^{-1}$.

statistical significance of the experimental data. The regression analysis describes the model of variation of the three chromatic coordinates. The results reported in Table 2 and in Figure 1 demonstrate that the various components exhibit a high statistical significance concerning every polynomial function used for the analysis.

In particular, the colour changes are reported as variations of the $L^{*} a^{*} b^{*}$ coordinates in function of time (Figure 1 ) as calculated from the regression analysis shown in Table 2.

As can be observed in the figure, wood colour varies with the exposure time; in particular, lightness $\left(L^{*}\right)$ values decrease markedly, whereas the chromaticity parameters $a^{*}$ and $b^{*}$ increase, as found also by other authors on different species $[3,17,18]$. In particular, as shown in Table $1, L^{*}$ value decreases from 84.3 to 71.6 . The $a^{*}$ and $b^{*}$ coordinates increase from 2.0 to 9.5 and from 16.8 to 33.3 , respectively. In 


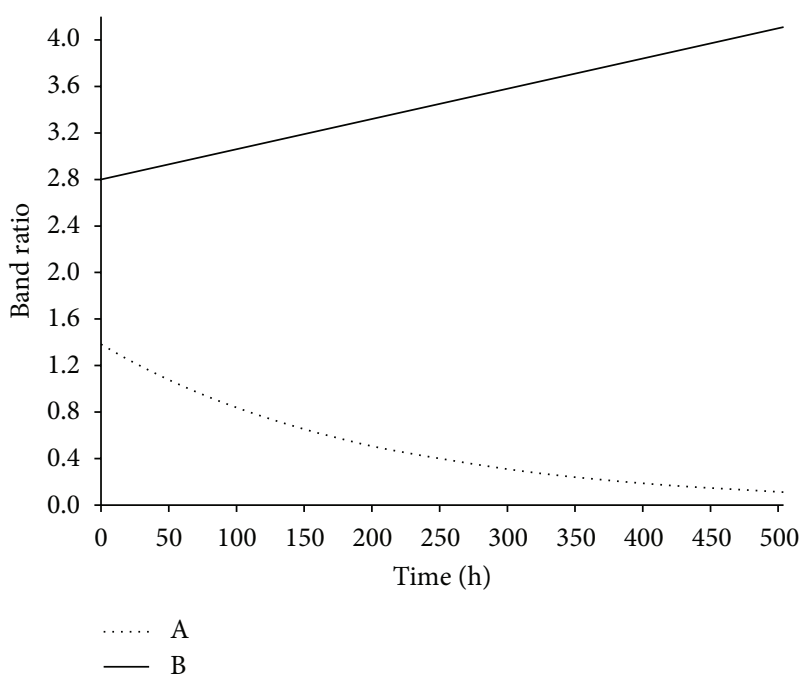

FIGURE 5: Change in the ratio band at different exposure times, as calculated from the regression analysis shown in Table 5 . In the legend (A: $\left.I_{1507} / I_{1376}\right)$, (B: $\left.I_{1737} / I_{1376}\right)$.

TABLE 1: Averages of the chromatic coordinates at different times of exposure in Solar Box for poplar samples. M-ANOVA test shows highly significant differences of the colorimetric parameters at different exposure times. Different letters indicate statistical differences (Tukey test, alfa $=0.01$ ).

\begin{tabular}{|c|c|c|c|c|c|c|}
\hline Time (h) & $L^{*}$ & HSD & $a^{*}$ & HSD & $b^{*}$ & HSD \\
\hline 0 & 84.3 & $\mathrm{a}$ & 2.0 & $b, c$ & 16.8 & $\mathrm{a}$ \\
\hline 1 & 83.7 & b & 1.4 & $\mathrm{a}$ & 16.7 & $\mathrm{a}$ \\
\hline 2 & 83.6 & $\mathrm{~b}$ & 1.3 & a & 17.1 & b \\
\hline 3 & 83.4 & b, c & 1.4 & a & 17.8 & c \\
\hline 4 & 83.8 & $a, b$ & 1.3 & a & 19.7 & d \\
\hline 5 & 83.3 & b, c & 1.4 & a & 19.6 & d \\
\hline 6 & 83.0 & $c, d$ & 1.5 & $\mathrm{a}$ & 19.7 & d \\
\hline 7 & 82.6 & d, e & 1.9 & $\mathrm{~b}$ & 20.7 & e \\
\hline 8 & 82.0 & $e, f$ & 2.0 & $b, c$ & 20.6 & e \\
\hline 9 & 81.7 & $\mathrm{f}$ & 2.0 & $b, c, d$ & 21.1 & $\mathrm{f}$ \\
\hline 10 & 82.0 & $\mathrm{f}$ & 2.1 & $b, c, d$ & 21.2 & $\mathrm{f}$ \\
\hline 11 & 81.9 & $\mathrm{f}$ & 2.1 & $c, d$ & 21.6 & g \\
\hline 12 & 81.9 & $\mathrm{f}$ & 2.1 & $\mathrm{~d}$ & 22.7 & $\mathrm{~h}$ \\
\hline 24 & 80.9 & g & 2.6 & e & 25.3 & $\mathrm{i}$ \\
\hline 48 & 80.0 & $\mathrm{~h}$ & 3.4 & $\mathrm{f}$ & 27.6 & 1 \\
\hline 72 & 79.7 & $\mathrm{~h}$ & 4.0 & g & 29.9 & $\mathrm{n}$ \\
\hline 96 & 78.3 & i & 4.5 & $\mathrm{~h}$ & 29.4 & $\mathrm{~m}$ \\
\hline 120 & 78.1 & $\mathrm{i}$ & 4.8 & $\mathrm{i}$ & 29.9 & $\mathrm{n}$ \\
\hline 144 & 77.9 & i & 5.2 & 1 & 30.3 & o \\
\hline 168 & 77.7 & $\mathrm{i}$ & 5.7 & $\mathrm{~m}$ & 31.4 & $\mathrm{p}$ \\
\hline 216 & 76.4 & 1 & 7.1 & $\mathrm{n}$ & 33.1 & $\mathrm{r}$ \\
\hline 312 & 72.7 & $\mathrm{~m}$ & 8.9 & o & 33.1 & $\mathrm{r}$ \\
\hline 408 & 71.7 & $\mathrm{n}$ & 8.7 & $\mathrm{p}$ & 32.2 & $q$ \\
\hline 504 & 71.6 & $\mathrm{n}$ & 9.5 & $\mathrm{q}$ & 33.3 & $\mathrm{r}$ \\
\hline
\end{tabular}

* Statistically significant.

general it is possible to state that the greatest change occurs within the first $24 \mathrm{~h}$ of exposure and around the $460 \mathrm{~nm}$ wavelength $(\Delta$ Reflectance\% $=-28.3)$ which corresponds in violet/blue shades, as deduced by the reflectance spectra (Figure 2). This correlates to an increase in yellow/red colouring and is in agreement with an increase of $b^{*}$ coordinate.

A nonlinear regression analysis with three dependent variables was applied to the time in function of colour coordinates (Table 3). The results shown in Table 3 underline the highly statistical significance of the obtained measures regarding the dependent variable time $(T)$ as function of the colour coordinates $\left(L^{*}, a^{*}, b^{*}\right)$.

Colour changes have been also analysed using $\Delta E^{*}$ variations as function of time exposure (Figure 3). After the first $72 \mathrm{~h}$ of exposure in Solar Box a rapid colour change in poplar wood can be observed, as reported also by Oltean et al. for black poplar [19]. The increases of $\Delta E^{*}$ become less marked over longer times but reach high values after 504 hours of exposure $\left(\Delta E^{*}=22.13\right.$ after $\left.504 \mathrm{~h}\right)$. By analyzing the obtained results, it is possible to suppose that the rapid decrease of lightness observed for the wood samples within the first 24 of exposure can be ascribed to photodegradation processes. The photodegradation is primarily related to the decomposition of lignin due to the chromophore groups absorbing energy, especially in the UV range of the sunlight spectrum $[3,20,21]$.

3.2. FT-IR Analysis on the Wood Slices. Concerning infrared spectroscopy on the samples, the spectra were collected in DRIFT modality directly on the wood slices in order to avoid analysing the unaltered wood also. In fact, wood is a good light absorber for infrared, visible, and ultraviolet light $[22,23]$. In particular the UV component of light is totally absorbed in a $75 \mu \mathrm{m}$-thick layer [21]. Since the change caused by irradiation appears in a thin surface layer, it is not easy to remove the proper thin layer for pellet preparation, as suggested also by other authors [24].

Band assignment was made according to literature references [12, 25-27]. FT-IR spectra are characterized by the following bands (Figure 4, $0 \mathrm{~h}$ ): $1737 \mathrm{~cm}^{-1}$ stretching of the carbonyl group $\mathrm{C}=\mathrm{O}, 1654 \mathrm{~cm}^{-1}$ conjugated carbonyl, $1595 \mathrm{~cm}^{-1}$ aromatical skeletal vibrations, $1507 \mathrm{~cm}^{-1}$ aromatic skeletal vibrations, $1464 \mathrm{~cm}^{-1} \mathrm{C}-\mathrm{H}$ deformation and aromatical skeletal vibrations, $1428 \mathrm{~cm}^{-1} \mathrm{C}-\mathrm{H}$ in-plane deformation, $1376 \mathrm{~cm}^{-1} \mathrm{C}-\mathrm{H}$ in-plane deformation for polysaccharides, $1333 \mathrm{~cm}^{-1}$ syringyl ring breathing and $\mathrm{C}-\mathrm{O}$ stretching, 1270$1245 \mathrm{~cm}^{-1}$ guaiacyl ring breathing and $\mathrm{C}-\mathrm{O}$ stretching, $1171 \mathrm{~cm}^{-1} \mathrm{C}-\mathrm{O}-\mathrm{C}$ antisymmetric bridge stretching vibration in cellulose and hemicelluloses, $1133 \mathrm{~cm}^{-1} \mathrm{C}-\mathrm{O}-\mathrm{C}$ symmetric stretching and aromatic $\mathrm{C}-\mathrm{H}$ in-plane deformation and glucose ring vibration, $1091 \mathrm{~cm}^{-1} \mathrm{C}-\mathrm{O}$ and $\mathrm{O}-\mathrm{H}$ association bands in cellulose and hemicelluloses, and $899 \mathrm{~cm}^{-1} \mathrm{C}_{1}-\mathrm{H}$ deformation of cellulose. The bands at $3400 \mathrm{~cm}^{-1}$ stretching of O-H group, $2940 \mathrm{~cm}^{-1}$ and $2906 \mathrm{~cm}^{-1} \mathrm{C}-\mathrm{H}$ and $\mathrm{CH}_{2}$ asymmetric and symmetric stretching, $672 \mathrm{~cm}^{-1} \mathrm{C}-\mathrm{OH}$ outof-plane bending in cellulose are not shown in Figure 4.

The irradiating time-dependent diffuse reflectance FT-IR spectra, in the region of interest of the present work, are shown in Figure 4. 


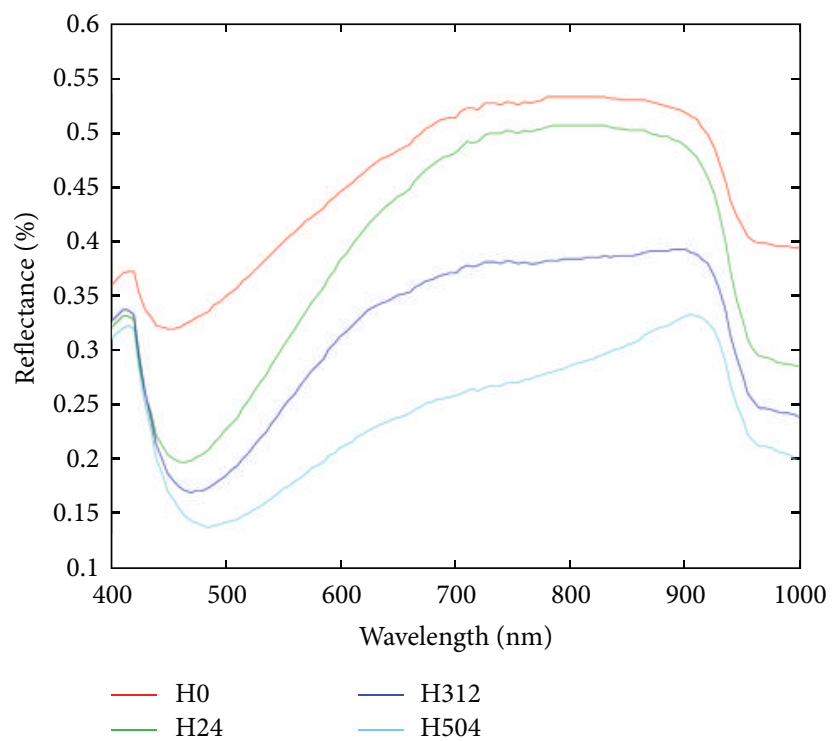

(a)

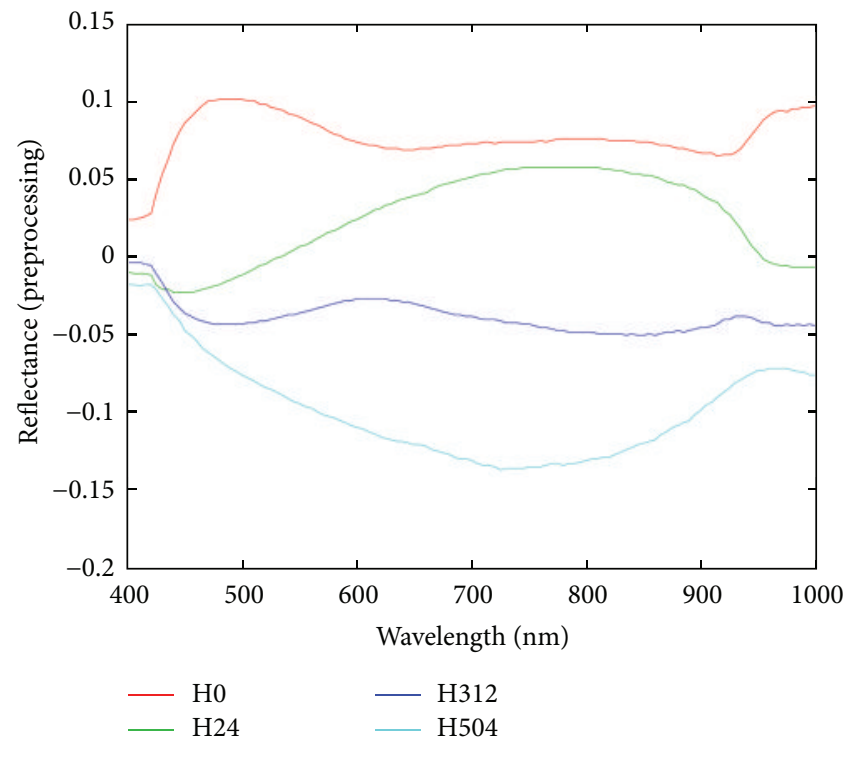

(b)

FIGURE 6: Acquired (a) and preprocessed (b) spectra of the different analysed wood slices, in the VIS-NIR field. Spectra preprocessing was carried out by adopting a GLSW procedure.

H0
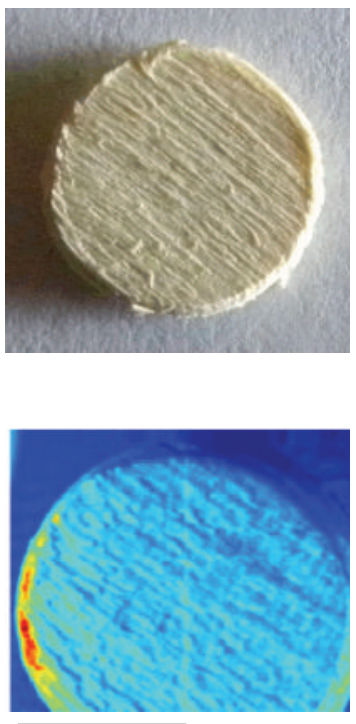

$5 \mathrm{~mm}$
H24
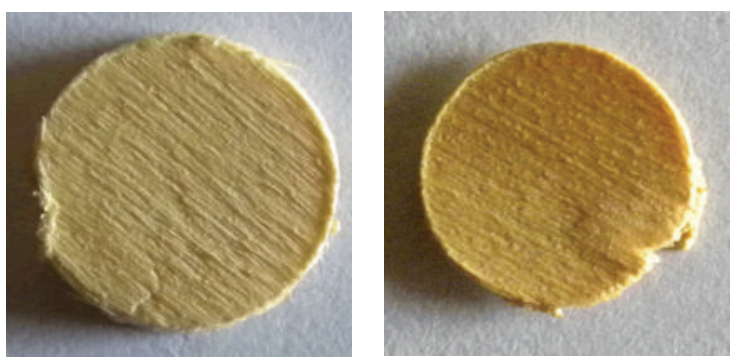

(a)
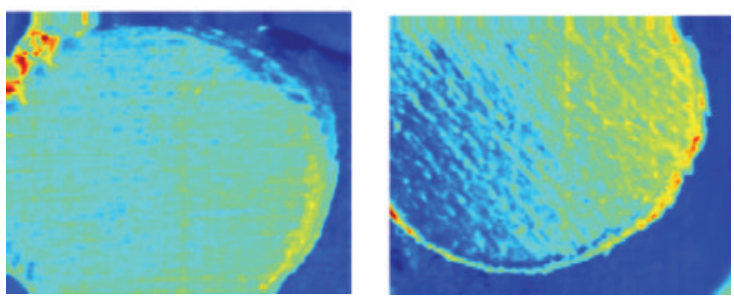

$5 \mathrm{~mm}$
$\mathrm{H} 504$
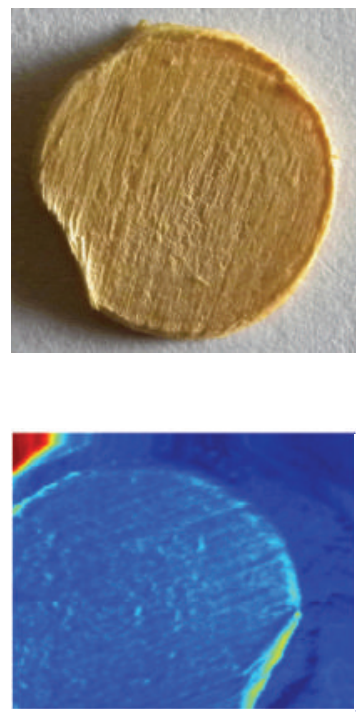

(b)

FIGURE 7: Images of the investigated poplar samples used to build the model. (a) acquired images and (b) images resulting from hypercube data rendering (i.e., false colours) according to the spectral response of the samples in the VIS-NIR range.

TABLE 2: Nonlinear regression analysis applied to the chromatic coordinates at different times of exposure in Solar Box for poplar samples.

\begin{tabular}{lcccccccc}
\hline Value & Intercept & Significance & time & Significance & time $^{2}$ & Significance & $R^{2}$ adj. & Significance \\
\hline$L^{*}$ & 83.002 & $* * *$ & -0.045 & $* * *$ & 0.00004 & $* * *$ & 0.816 & $* * *$ \\
$a^{*}$ & 1.569 & $* * *$ & 0.032 & $* * *$ & -0.00003 & $* * *$ & 0.954 & $* * *$ \\
$b^{*}$ & 20.108 & $* * *$ & 0.00679 & $* * *$ & -0.00008 & $* * *$ & 0.857 & $* * *$ \\
\hline
\end{tabular}

* Statistically significant.

${ }^{* * *}$ Very high statistical significance. 
TABLE 3: Nonlinear regression analysis applied to the time as function of the chromatic coordinates.

\begin{tabular}{lcc}
\hline \multicolumn{3}{c}{ Poplar samples } \\
& $\mathrm{B}$ & Significance \\
\hline Intercept & 1732.326 & $* * *$ \\
$L^{*}$ & -56.232 & $* * *$ \\
$a^{*}$ & 16.154 & $* * *$ \\
$b^{*}$ & 24.495 & $* * *$ \\
$L^{* 2}$ & 0.381 & $* * *$ \\
$a^{* 2}$ & 4.376 & $* * *$ \\
$b^{* 2}$ & -0.520 & $* * *$ \\
\hline$R^{2}$ adj. $=0.947 ; P<0.001$. & \\
$T=1732.3-56.2 L^{*}+16.2 a^{*}+24.5 b^{*}+0.4 L^{* 2}+4.4 a^{* 2}$. \\
${ }^{*}$ Statistically significant. \\
${ }^{* * *}$ Very high statistical significance.
\end{tabular}

It can be observed that the intensity of the bands at $1507 \mathrm{~cm}^{-1}, 1595 \mathrm{~cm}^{-1}$, and $1464 \mathrm{~cm}^{-1}$, associated to lignin, decreases during photo degradation. This is accompanied by an increase in the intensity of the band at $1737 \mathrm{~cm}^{-1}$, due to carbonyl absorption. The intensities of the peak associated to carbohydrates at $1376 \mathrm{~cm}^{-1}$ are not significantly affected by irradiation, so this band has been used as internal reference to evaluate the lignin degradation.

In order to determine the rate of lignin degradation and carbonyl formation, the intensities of the lignin band at $1507 \mathrm{~cm}^{-1}$, the carbonyl band at $1737 \mathrm{~cm}^{-1}$, and the carbohydrate reference band at $1376 \mathrm{~cm}^{-1}$ were calculated [12]. Then the relative change in ratio of lignin/carbohydrate bands at different exposure times was derived and statistically evaluated.

In particular, two-way ANOVA was applied to the infrared peak values to test if significant differences in relation to the samples and to the time could be found. Table 4 shows the results of the two-way ANOVA test. As can be observed in Table 4 the differences in the peak ratio with respect to the exposure times are highly significant concerning the $I_{1507} / I_{1376}$ ratio. The difference is only significant as regards the $I_{1737} / I_{1376}$ ratio.

Nonlinear regression analysis was also applied to the peak ratio at the different times of exposure in Solar Box. The results are shown in Table 5 and in Figure 5.

The lignin/carbohydrate intensity ratio decreased with the exposure times (as visible in Figure 6, curve (a)), and after $48 \mathrm{~h}$ of irradiation the experimental value of the $I_{1507} / I_{1376}$ ratio decreased to about $50 \%$ of its original value.

The relative increase of the carbonyl groups during photo irradiation was calculated by considering the ratio of intensity of carbonyl band at $1737 \mathrm{~cm}^{-1}$ against reference peak at $1376 \mathrm{~cm}^{-1}$. The intensity of the band of the carbonyl groups increases as function of irradiation time. This can be explained with the photo-oxidation reactions of lignin [28].

The regression analysis clearly demonstrates that for the $I_{1507} / I_{1376}$ peak ratios a statistically significant regression has been derived from the experimental data. In the case of the $I_{1737} / I_{1376}$ peak ratio the regression has a low statistical significance.

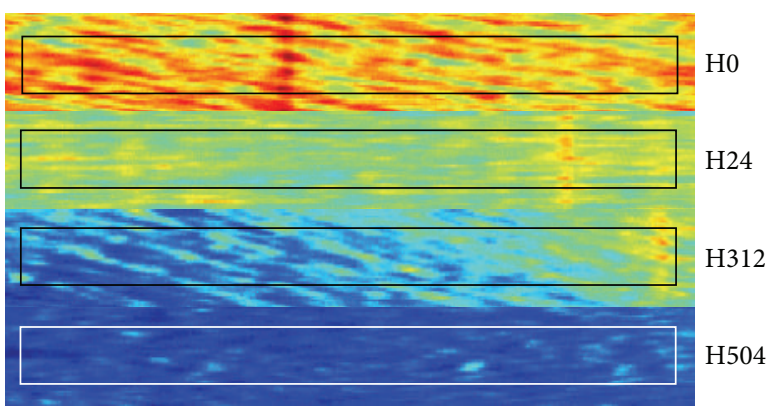

FIGURE 8: Reconstructed sample image, obtained performing a cut in the central region of each sample. It was used to perform the hyperspectral-based classification. The ROIs used as training set are also shown in the image for each of the four classes.

At last the colour changes of wood during irradiation were correlated with lignin degradation and the formation of carbonyl groups produced by the photo degradation process. In fact, as the colour changes of the surfaces are mainly due to the photo-degradation of lignin, there would be a correlation between the colour coordinates and the relative intensity of the infrared peaks associated to lignin. The results shown in Table 6 demonstrate that the lignin degradation is related to photo-induced colour changes of wood surfaces.

3.3. Hyperspectral Imaging on the Wood Slices: Investigations in the VIS-NIR Wavelength Range. The acquired and the preprocessed spectra for the different irradiated wood slices, at times $0(\mathrm{H} 0), 24(\mathrm{H} 24), 312(\mathrm{H} 312)$, and 504 hours (H504) of exposure, are shown in Figure 6. Spectra have been collected starting from areas selected on the wood sample surfaces. The source wood spectra related to the different exposure times are characterized by a similar shape, especially $\mathrm{H} 0$ and $\mathrm{H} 24$, with a difference in the region around $700-900 \mathrm{~nm}$ that becomes more evident at $\mathrm{H} 312$ and H504. Moreover, the reflectance decreases from $\mathrm{H} 0$ to H504. The application of GLSW preprocessing strongly highlights the differences between the 4 different exposure times.

Figures 7 and 8 show, respectively, the false colour images, as resulting from hypercube data structure, and the reconstructed sample image obtained utilizing the Region of Interest (ROIs) selected in each sample and used to perform the spectral data collection and analysis.

The results of PCA are shown in Figure 9. The greater part of the variance is captured by the first two PCs, as shown in the score plot, where PC1 and PC2 explain $75.11 \%$ and $6.71 \%$ of the variance, respectively. The spectral data of the four wood samples are clustered into four distinct groups according to their spectral signatures. Discrimination between the wood samples characterized by different exposure times is obtained, especially concerning $\mathrm{H} 0, \mathrm{H} 24$, and H504, whereas $\mathrm{H} 312$ is more dispersed between $\mathrm{H} 24$ and $\mathrm{H} 504$.

The PLS-DA-based classification was calculated using the same pretreatment technique adopted to perform PCA (GLSW) analyses for reference class definition. Starting from 4 new samples, the same approach previously outlined was 
TABLE 4: Two-way ANOVA test applied to the peak ratios in relation to the poplar samples and to the irradiation time.

\begin{tabular}{lccccc}
\hline Peak ratio & Measures Nr. & Average & Std. Dev. & Samples differences & Time differences \\
\hline$I_{1507} / I_{1376}$ & 42 & 0.827 & 0.490 & No significance & $* * *$ \\
$I_{1740} / I_{1376}$ & 42 & 3.210 & 1.030 & No significance & $* *$ \\
\hline
\end{tabular}

${ }^{* * *}$ High statistical significance.

**** Very high statistical significance.

TABle 5: Nonlinear regression analysis for the peak ratio at the different times of exposure in Solar Box of poplar samples.

\begin{tabular}{|c|c|c|c|c|c|c|c|}
\hline Value & Coefficient & Description & Significance & Time coefficient & Significance & $R^{2}$ adj. & Significance \\
\hline $\begin{array}{l}I_{1507} / I_{1376} \\
\text { Regression }\end{array}$ & \multicolumn{6}{|c|}{$I_{1507} / I_{1376}=1.383 e^{-0.005 t}$} & $* * *$ \\
\hline $\begin{array}{l}I_{1737} / I_{1376} \\
\text { Regression }\end{array}$ & 2.808 & intercept & $* * *$ & $\begin{aligned} & 0.003 \\
I_{1376}= & 2.808+0.00\end{aligned}$ & $*$ & 0.129 & * \\
\hline
\end{tabular}

*Statistically significant.

*** Very high statistical significance.

TABLE 6: Nonlinear regression analysis applied to the peak ratio as function of the chromatic coordinates $L^{*} a^{*} b^{*}$ in poplar wood.

\begin{tabular}{lcc}
\hline & $I_{1507} / I_{1376}$ \\
& $\mathrm{~B}$ & Significance \\
\hline Intercept & 1.4582 & $* * *$ \\
$L^{2 *}$ & 0.000092 & $* * *$ \\
$a^{2 *}$ & -0.00373 & $* * *$ \\
$b^{2 *}$ & -0.001328 & $* * *$ \\
\hline$R^{2}$ adj. $=0.999$. & \\
$I_{1507} / I_{1376}=1.4582+0.000092 L^{* 2}-0.00373 a^{* 2}-0.001328 b^{* 2}$. \\
${ }^{*}$ Statistically significant.
\end{tabular}

thus applied, that is, (i) construction of a sample image to verify PLS-DA model, starting from four different ROIs selected inside the wood samples in order to avoid "border effects" (Figure 10); (ii) selection of ROIs, inside the reconstructed sample image, to collect spectra representative of the different irradiated wood slices in order to validate the model.

The results, reported in Figure 11 as prediction images, indicate that the PLS-DA models allow obtaining a good classification of all the samples. Such results can be evaluated taking into account the values of sensitivity and specificity parameters obtained for the classification model. These parameters range from 0 to 1,1 being the ideal value for a prediction model. Sensitivity is defined as the proportion of class members correctly classified, while specificity refers to the proportion of nonclass members correctly classified.

The sensitivity and specificity of the PLS-DA model are reported in Table 7 both for Calibration and CrossValidation. The values of sensitivity and specificity range between $0.75(\mathrm{H} 312)$ and $0.996(\mathrm{H} 0)$ for Calibration and between 0.74 (H312) and 0.996 (H0) for Cross-Validation. Good values of sensitivity and specificity are obtained for the classification of the different time-exposed wood samples, indicating the robustness of the model. The sample exposed for 312 hours was confirmed as the worst classified according

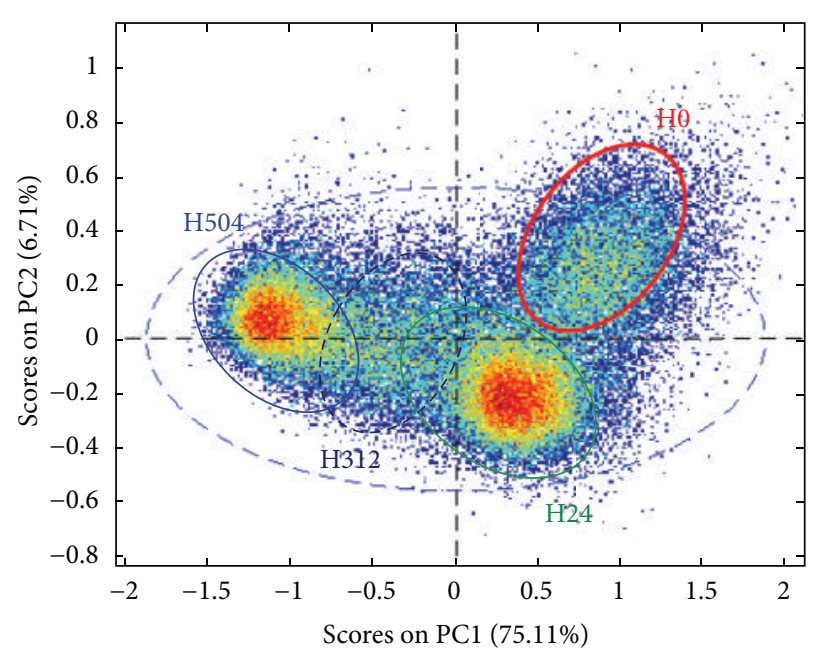

FIgURE 9: Score plot (PC1 versus PC2), obtained using 81 wavelengths, based on average HSI spectral signatures in the VIS-NIR wavelength region $(400-900 \mathrm{~nm})$ for the analysed poplar wood samples.

to the indications obtained during the explorative analysis based on PCA previously carried out and described.

3.4. Hyperspectral Imaging on the Wood Slices: Investigations in the SWIR Wavelength Range. The acquired and the preprocessed spectra for the different irradiated wood slices, at times 0 (H0), 216 (H216), and 504 hours (H504) of exposures are shown in Figure 12. In the SWIR range both cellulose and lignin are characterised by absorption bands corresponding to specific wavelengths, that is, $1220,1480,1930,2100,2280$, 2340, and $2480 \mathrm{~nm}$ for cellulose and 1450, 1680, 1930, 2270, 2330, 2380, and $2500 \mathrm{~nm}$ for lignin [29].

The strong absorptions at around $1460 \mathrm{~nm}$ and $1930 \mathrm{~nm}$ can be attributed to the combination modalities of $\mathrm{OH}$ in water molecules. It should be noted that the water chemical bond vibration around $1460 \mathrm{~nm}$ may overlap with those of 

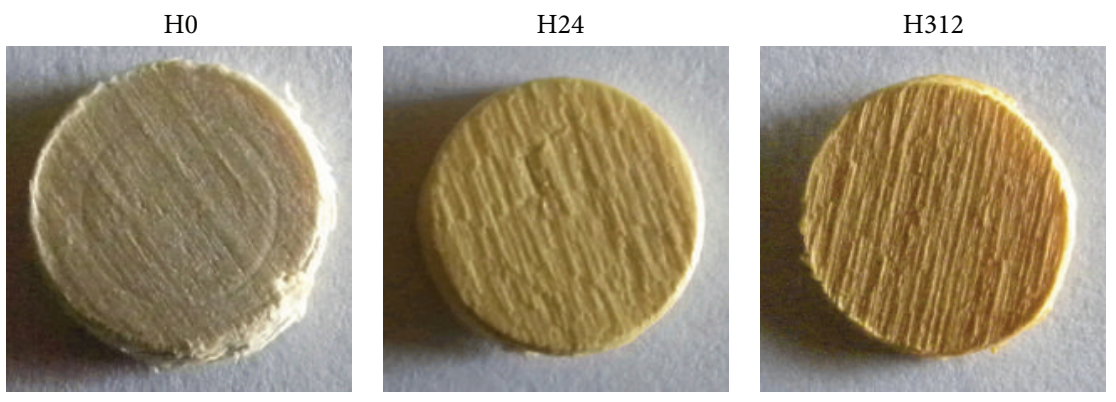

(a)

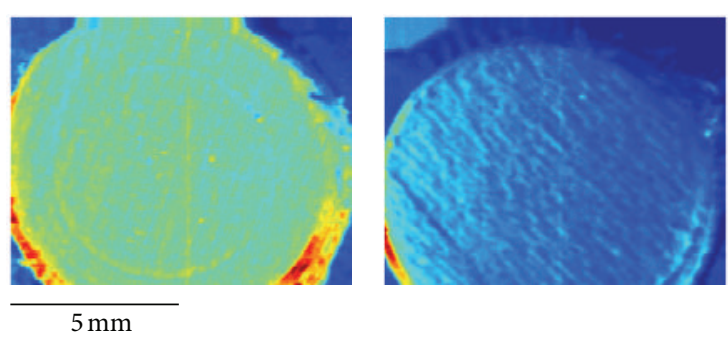

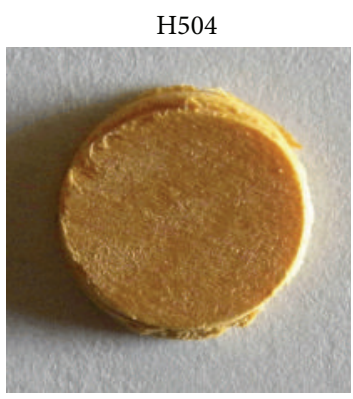

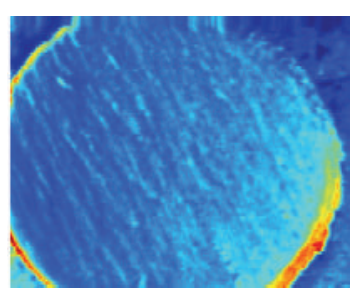

$5 \mathrm{~mm}$

(b)

FIGURE 10: Images of the investigated poplar samples used to perform the PLS-DA-based classification. (a) images as acquired and (b) images as resulting from hypercube data rendering (i.e., false colours) according to samples spectral response in the VIS-NIR range.

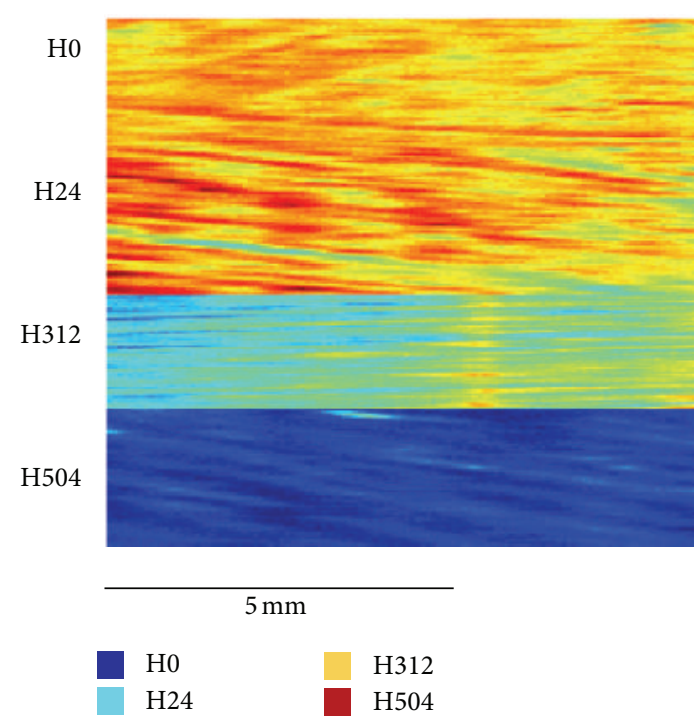

(a)

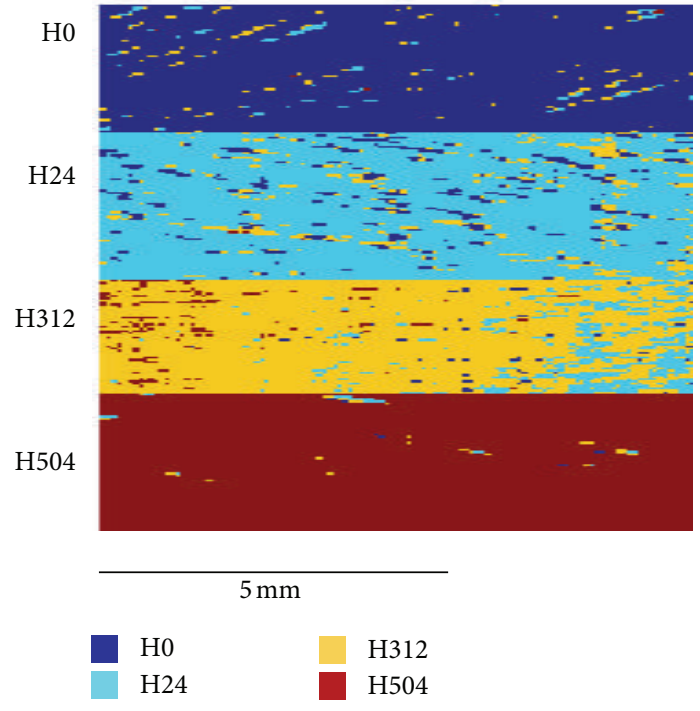

(b)

FIGURE 11: Reconstructed sample image, obtained combining the four different selected ROIs inside the different wood samples and used to perform the hyperspectral-based PLS-DA model validation (a). PLS-DA prediction (most probable class prediction) (b).

other $\mathrm{OH}$ groups in cellulose molecules or of $\mathrm{CH}_{2}$ groups in lignin [29], making the accurate band assignment in this region difficult. The weak spectral feature around $1730 \mathrm{~nm}$ may be attributed to the presence of $\mathrm{OH}$ bond of water molecule in cellulose/lignin and the weak absorption at $1790 \mathrm{~nm}$ to $\mathrm{O}-\mathrm{H}$ stretching in water molecules. The mean absorptions in the $2000-2500 \mathrm{~nm}$ wavelength interval can be attributed to the various configurations of the $\mathrm{C}-\mathrm{H}, \mathrm{C}=\mathrm{O}$, $\mathrm{C}=\mathrm{C}$, and $-\mathrm{COOH}$ functional groups in cellulose and lignin.
Spectra were acquired by performing a preliminary background removal as, differently from the VIS-NIR case, spectral data collection and analysis were carried out with reference to the entire surface of each wood sample. Figures 13 and 14 show, respectively, the false colour images, as resulting from hypercube data structure, and the reconstructed sample image obtained after the background removal.

The results of PCA, applied to the average spectral signature of the investigated wood samples, are shown in 
TABLE 7: Sensitivity and specificity for the PLS-DA model built for the different wood samples, based on 81 wavelengths.

\begin{tabular}{lccccc}
\hline & & Class 1 (H0) & Class 2 (H24) & Class 3 (H312) & Class 4 (H504) \\
\hline \multirow{2}{*}{ Sensitivity } & Calibration & 0.996 & 0.972 & 0.788 & 0.972 \\
& Cross-validation & 0.996 & 0.971 & 0.776 & 0.971 \\
Specificity & Calibration & 0.990 & 0.941 & 0.746 & 0.932 \\
& Cross-validation & 0.989 & 0.938 & 0.744 & 0.930 \\
\hline
\end{tabular}

TABLE 8: Sensitivity and specificity for the PLS-DA model built for the different wood samples, based on 240 wavelengths.

\begin{tabular}{lcccc}
\hline & & Class 1 (H0) & Class 2 (H216) & Class 3 (H504) \\
\hline \multirow{2}{*}{ Sensitivity } & Calibration & 0.971 & 0.896 & 0.969 \\
& Cross-validation & 0.967 & 0.868 & 0.966 \\
Specificity & Calibration & 0.993 & 0.965 & 0.960 \\
& Cross-validation & 0.993 & 0.962 & 0.960 \\
\hline
\end{tabular}

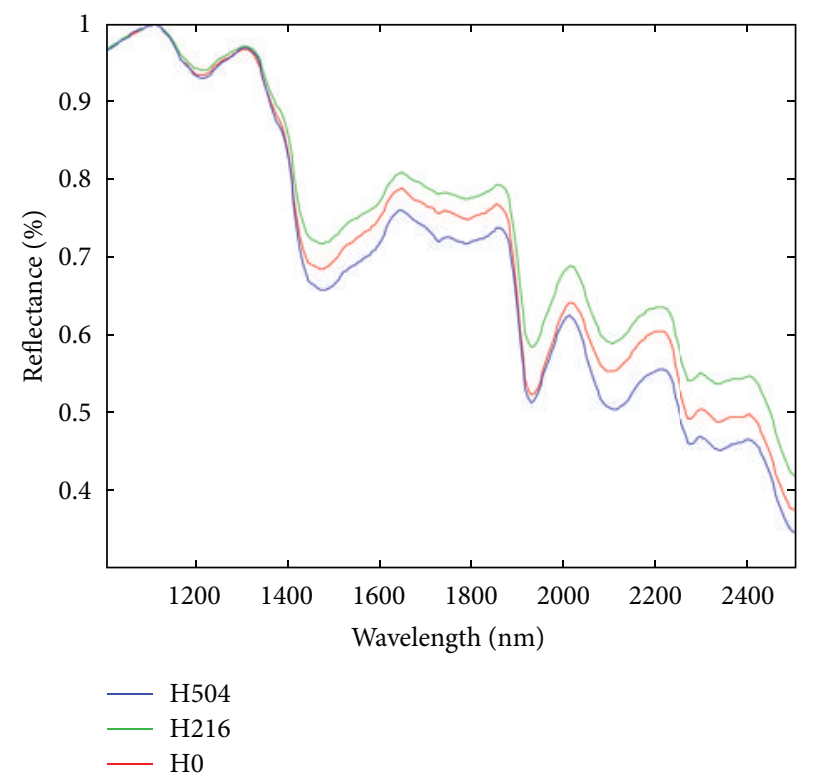

(a)

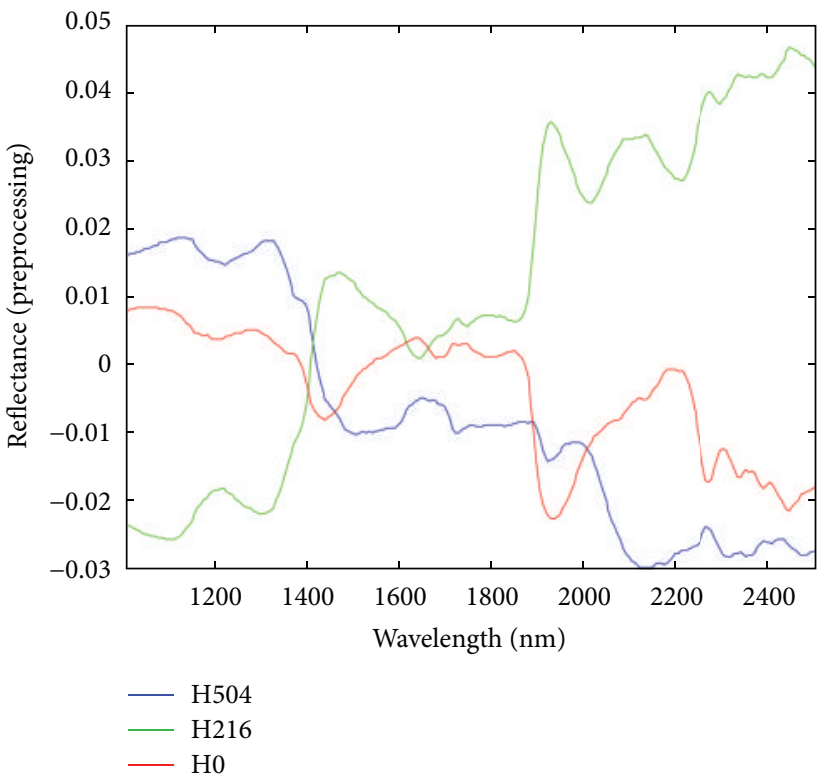

(b)

FIGURE 12: Acquired (a) and preprocessed (b) spectra of the different analysed wood slices, in the SWIR field. Spectra preprocessing was carried out adopting a GLSW procedure.

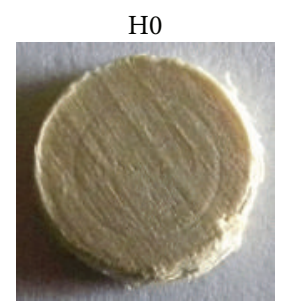

$1 \mathrm{~cm}$

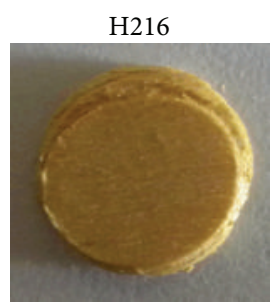

(a)
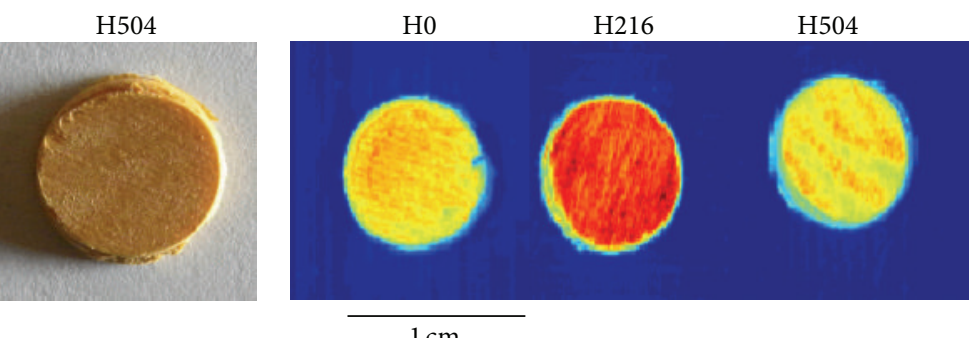

(b)

FIGURE 13: Images of the investigated poplar sample used to build the model. (a) acquired images and (b) images resulting from the hypercube data rendering (i.e., false colours) according to the sample spectral response in the SWIR range. 


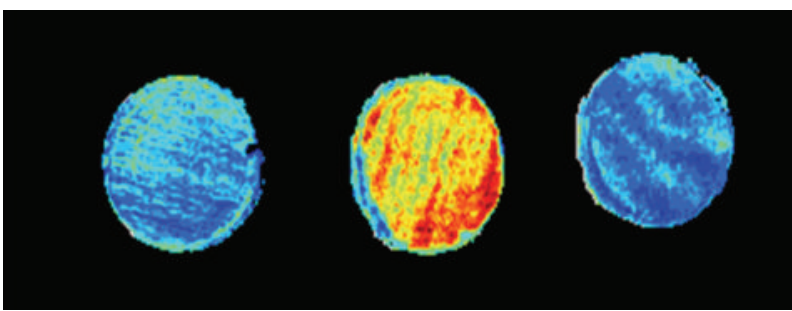

FIGURE 14: Reconstructed sample image, obtained after a preliminary background removal. It was used to perform the hyperspectral-based classification.

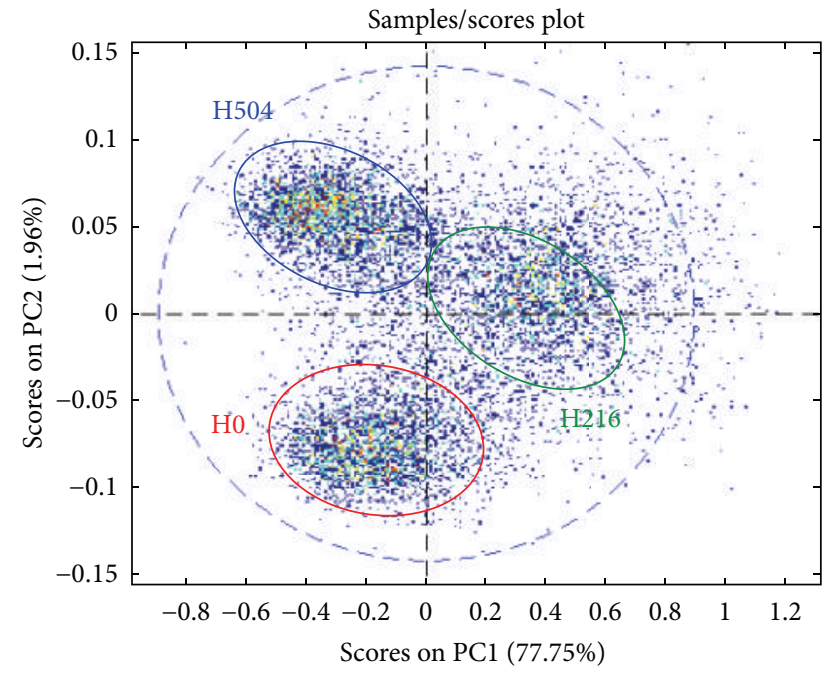

Figure 15: Score plot (PC1 versus PC2), obtained using 240 wavelengths, based on average HSI spectral signatures in the SWIR wavelength region $(1005-2500 \mathrm{~nm})$, of the analysed poplar wood samples.

Figure 15. The greater part of the variance was captured by the first two PCs, as shown in the score plot, where PC1 and PC2 explained $77.75 \%$ and $1.96 \%$ of the variance, respectively. The spectral data of the three wood samples are clustered into three distinct groups according to their spectral signatures. A discrimination between the wood samples characterized by different exposure times is thus obtained.

The PLS-DA model was developed, as in the VIS-NIR study, to perform a prediction (i.e., recognition/classification) on unknown wood samples characterised by different exposure times. The PLS-DA-based classification was calculated using the same pretreatment technique adopted to perform PCA (GLSW) analysis for reference class definition. Starting from 3 new samples the following approach was applied: (i) construction of a sample image to verify PLS-DA model, performing background elimination (Figure 16) and (ii) collection of all the spectra related to each sample in order to validate the model (Figure 17).

The sensitivity and specificity of the PLS-DA model, based on all 240 wavelengths, are reported in Table 8 both for Calibration and Cross-Validation. The values of sensitivity and specificity range between 0.896 (H24) and 0.993 (H0) for Calibration and between 0.868 (H24) and 0.993 (H0) for
Cross-Validation. The results (Figure 17) indicate that the PLSDA models allowed reaching, as in the VIS-NIR range, a good recognition/classification, according to their irradiation times for the 3 investigated poplar samples.

\section{Conclusions}

The study of colour changes in poplar samples showed that the wood surface undergoes an important variation due to photo irradiation. The greatest changes occur within the first 24 hours, and they are mainly due to $L^{*}$ decrease and $b^{*}$ increase. M-ANOVA and Tukey tests underline that $L^{*}$, $a^{*}$, and $b^{*}$ undergo statistically significant changes after the exposure times further demonstrating that surface wood colour remarkably changes due to the irradiation in Solar Box. The regression analysis, applied both to the chromatic coordinates as function of the time and vice versa, underlines the highly statistical significance of the experimental data.

FT-IR spectroscopy allowed investigating the rate of photo degradation of wood surface due to lignin oxidation. The rate of photo degradation of wood surface was investigated by studying the lignin/carbohydrate intensity ratio as function of time. The results put in evidence that lignin degrades quickly: after 48 hours of irradiation the lignin/carbohydrate ratio $\left(I_{1507} / I_{1376}\right)$ decreased to about $50 \%$ of its original value. The regression analysis applied to the infrared peak ratios demonstrated that the differences between the values at the various irradiation times are statistically significant, apart from the $I_{1737} / I_{1376}$ ratio.

Moreover a correlation between the colour changes and the chemical modifications was investigated in order to assess the applicability of colorimetric measurements in totally non invasive modality on the works of art. The most important result was that a correlation of the colour changes may be derived with the photo degradation of lignin obtained by FTIR analysis. This finding demonstrates that non invasive colour measurements can be used to evaluate the photo degradation of wood. In particular the regression analysis showed that the lignin degradation is related to the photoinduced colour variations of wood surfaces expressed by the $L^{*} a^{*} b^{*}$ coordinates.

Concerning hyperspectral imaging, the detected spectral features shown in the VIS-NIR range are mainly linked to the spectral shape (i.e., colour variation), whereas in the SWIR 


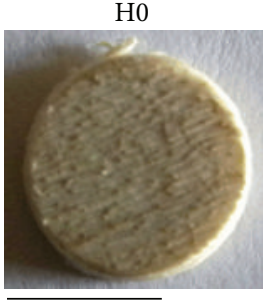

$5 \mathrm{~mm}$
$\mathrm{H} 216$

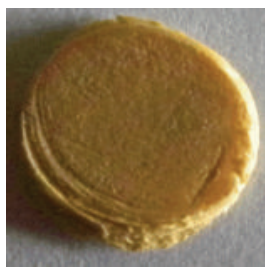

(a)
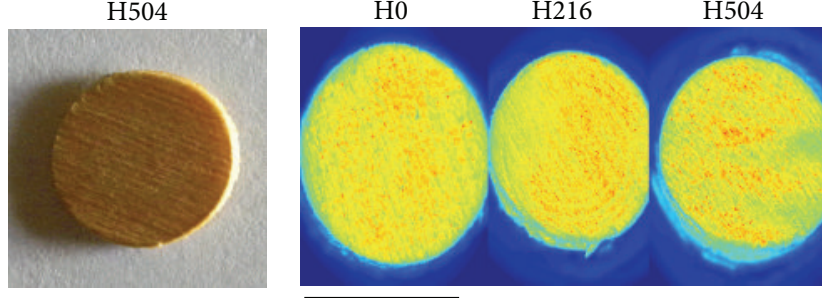

$5 \mathrm{~mm}$

(b)

FIGURE 16: Images of the investigated poplar samples used for the PLS-DA-based classification. (a) Acquired images and (b) images resulting from hypercube data rendering (i.e., false colours) according to samples spectral response in the SWIR range.

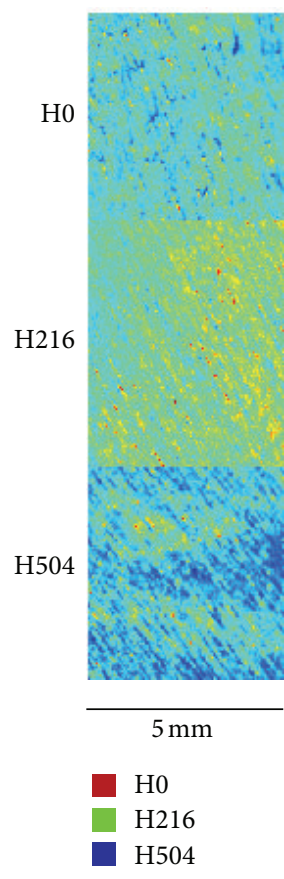

(a)

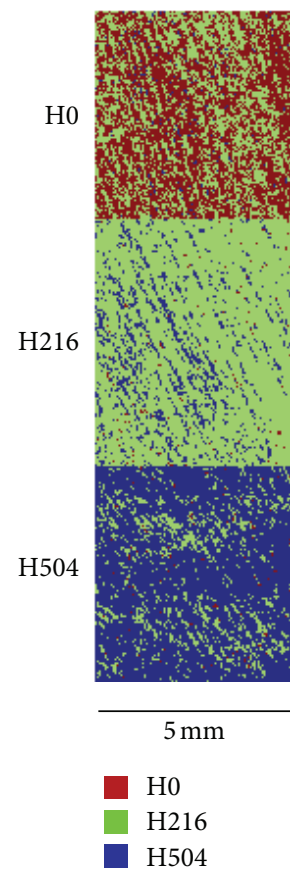

(b)

FIGURE 17: Reconstructed sample image, obtained by combining three different ROIs inside the different wood samples and utilised to perform the hyperspectral-based PLS-DA model validation (a). PLS-DA prediction (most probable class prediction) (b).

range cellulose and lignin affect both shape and reflectance levels.

The PCA applied to hyperspectral images acquired in the wavelength range $400-1000 \mathrm{~nm}$ highlighted a significant variation between samples not exposed and exposed after 24 hours. The variations between samples irradiated for 312 and 504 hours are lower, if compared with the previous ones; in any case the results showed that the colour changes are correlated with the lignin photo degradation. Concerning the SWIR, the PCA demonstrated a correlation between sample spectral profile characteristics and the exposure times.

The application of partial least squares regression (PLSDA) allowed performing a good classification and recognition of different irradiated samples in both investigated wavelength ranges. The proposed approach clearly showed that a correlation can be established between colour variation and wood degradation in the VIS-NIR; furthermore in the SWIR range wood surface chemical changes can be assessed.

\section{Disclosure}

The authors declare that they have no financial interests in this work.

\section{References}

[1] E. Marengo, E. Robotti, M. C. Liparota, and M. C. Gennaro, "A method for monitoring the surface conservation of wooden objects by Raman spectroscopy and multivariate control charts," Analytical Chemistry, vol. 75, no. 20, pp. 5567-5574, 2003.

[2] E. Marengo, E. Robotti, M. C. Liparota, and M. C. Gennaro, "Monitoring of pigmented and wooden surfaces in accelerated 
ageing processes by FT-Raman spectroscopy and multivariate control charts," Talanta, vol. 63, no. 4, pp. 987-1002, 2004.

[3] K. K. Pandey, "Study of the effect of photo-irradiation on the surface chemistry of wood," Polymer Degradation and Stability, vol. 90, no. 1, pp. 9-20, 2005.

[4] A. Lo Monaco, M. Marabelli, C. Pelosi, and R. Picchio, "Colour measurements of surfaces to evaluate the restoration materials," in O3A: Optics for Arts, Architecture, and Archaeology III, vol. 8084 of Proceedings of SPIE, pp. 1-14, May 2011.

[5] A. Lo Monaco, C. Pelosi, and R. Picchio, "Colour evolution of wood surfaces in simulated sunlight exposure," in Proceedings of the 7th Color Conference, SIOF: Color and Colorimetry. Multidisciplinary Contributions, vol. 7B, pp. 207-214, 2011.

[6] G. Genco, A. Lo Monaco, C. Pelosi, R. Picchio, and U. Santamaria, "A study of colour change due to accelerated sunlight exposure in consolidated wood samples," Wood Research, vol. 56, no. 4, pp. 511-524, 2011.

[7] C. Pelosi, G. Agresti, L. Calienno et al., "Application of spectroscopic techniques for the study of the surface changes in poplar wood and possible implications in conservation of wooden artefacts," in Optics for Arts, Architecture, and Archaeology IV, vol. 8790 of Proceedings of SPIE, pp. 1-14, 2013.

[8] M. Y. Pillow, "A new method for detecting compression wood," Journal of Forestry, vol. 39, no. 4, pp. 385-387, 1941.

[9] J. Nystrom and O. Hagman, "Methods for detecting compression wood in green and dry conditions," Journal of Wood Science, vol. 45, no. 1, pp. 30-37, 1999.

[10] J. C. Noordam, W. H. A. M. van den Broek, P. Geladi, and L. M. C. Buydens, "A new procedure for the modelling and representation of classes in multivariate images," Chemometrics and Intelligent Laboratory Systems, vol. 75, no. 2, pp. 115-126, 2005.

[11] A. Thumm, M. Riddell, B. Nanayakkara, J. Harrington, and R. Meder, "Near infrared hyperspectral imaging applied to mapping chemical composition in wood samples," Journal of Near Infrared Spectroscopy, vol. 18, no. 6, pp. 507-515, 2010.

[12] K. K. Pandey and A. J. Pitman, "FTIR studies of the changes in wood chemistry following decay by brown-rot and white-rot fungi," International Biodeterioration and Biodegradation, vol. 52, no. 3, pp. 151-160, 2003.

[13] P. Geladi, H. Grahn, and J. Burger, "Multivariate images, hyperspectral imaging: background and equipment," in Techniques and Applications of Hyperspectral Image Analysis, H. Grahn and P. Geladi, Eds., pp. 1-15, John Wiley \& Sons, West Sussex, UK, 2007.

[14] M. Otto, Chemometrics, Statistics and Computer Application in Analytical Chemistry, Wiley-VCH, New York, NY, USA, 1999.

[15] M. Barker and W. Rayens, "Partial least squares for discrimination," Journal of Chemometrics, vol. 17, no. 3, pp. 166-173, 2003.

[16] R. C. Ferreira, A. Lo Monaco, R. Picchio, A. Schirone, F. Vessella, and B. Schirone, "Wood anatomy and technological properties of an endangered species: Picconia azorica (Oleaceae)," IAWA Journal, vol. 33, no. 4, pp. 375-390, 2012.

[17] V. Sharratt, C. A. S. Hill, and D. P. R. Kint, "A study of early colour change due to simulated accelerated sunlight exposure in Scots pine (Pinus sylvestris)," Polymer Degradation and Stability, vol. 94, no. 9, pp. 1589-1594, 2009.

[18] L. Tolvaj and K. Mitsui, "Correlation between hue angle and lightness of light irradiated wood," Polymer Degradation and Stability, vol. 95, no. 4, pp. 638-642, 2010.
[19] L. Oltean, A. Teischinger, and C. Hansmann, "Wood surface discolouration due to simulated indoor sunlight exposure," Holz als Roh und Werkstoff, vol. 66, no. 1, pp. 51-56, 2008.

[20] X. Deglise and A. Merlin, "Comportement photochimique du bois non traité," in Durabilite des Bois, D. Dirol and X. Deglise, Eds., pp. 229-268, Herès Science Publication, Paris, France, 2002.

[21] D. N. S. Hon and N. Shiraishi, "Color and discoloration and Weathering and photochemistry of wood," in Wood and Cellulose Chemistry, pp. 385-442, 513-546, Marcel Dekker, New York, NY, USA, 2001.

[22] Y. Kataoka and M. Kiguchi, "Depth profiling of photo-induced degradation in wood by FT-IR microspectroscopy," Journal of Wood Science, vol. 47, no. 4, pp. 325-327, 2001.

[23] B. George, E. Suttie, A. Merlin, and X. Deglise, "Photodegradation and photostabilisation of wood-the state of the art," Polymer Degradation and Stability, vol. 88, no. 2, pp. 268-274, 2005.

[24] L. Tolvaj, K. Mitsui, and D. Varga, "Validity limits of KubelkaMunk theory for DRIFT spectra of photodegraded solid wood," Wood Science and Technology, vol. 45, no. 1, pp. 135-146, 2011.

[25] A. K. Moore and N. L. Owen, "Infrared spectroscopic studies of solid wood," Applied Spectroscopy Reviews, vol. 36, no. 1, pp. 65-86, 2001.

[26] H.-T. Chang, T.-F. Yeh, and S.-T. Chang, "Comparisons of chemical characteristic variations for photodegraded softwood and hardwood with/without polyurethane clear coatings," Polymer Degradation and Stability, vol. 77, no. 1, pp. 129-135, 2002.

[27] X. Colom, F. Carrillo, F. Nogués, and P. Garriga, "Structural analysis of photodegraded wood by means of FTIR spectroscopy," Polymer Degradation and Stability, vol. 80, no. 3, pp. 543-549, 2003.

[28] D. Rosu, C.-A. Teaca, R. Bodirlau, and L. Rosu, "FTIR and color change of the modified wood as a result of artificial light irradiation," Journal of Photochemistry and Photobiology B, vol. 99, no. 3, pp. 144-149, 2010.

[29] F. D. van der Meer and S. M. Jong, Eds., Imaging Spectrometry: Basic Principles and Prospective Applications, vol. 4 of Remote Sensing and Digital Image Processing, Springer, Dordrecht, The Netherlands, 2002. 

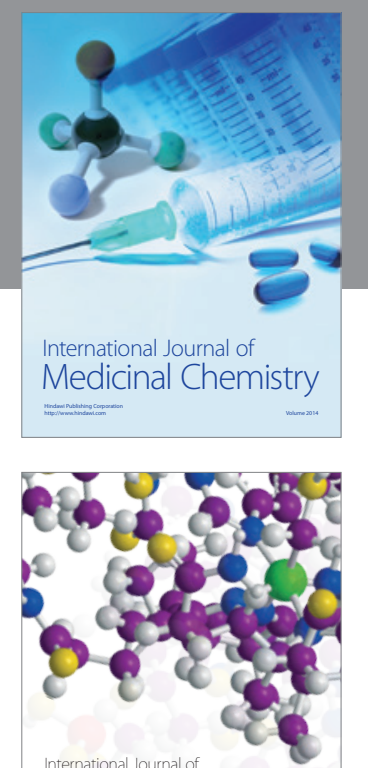

\section{Carbohydrate} Chemistry

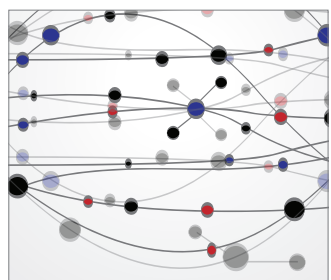

The Scientific World Journal
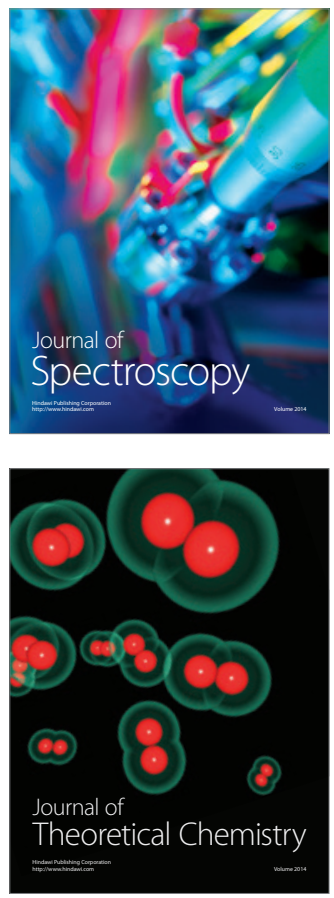
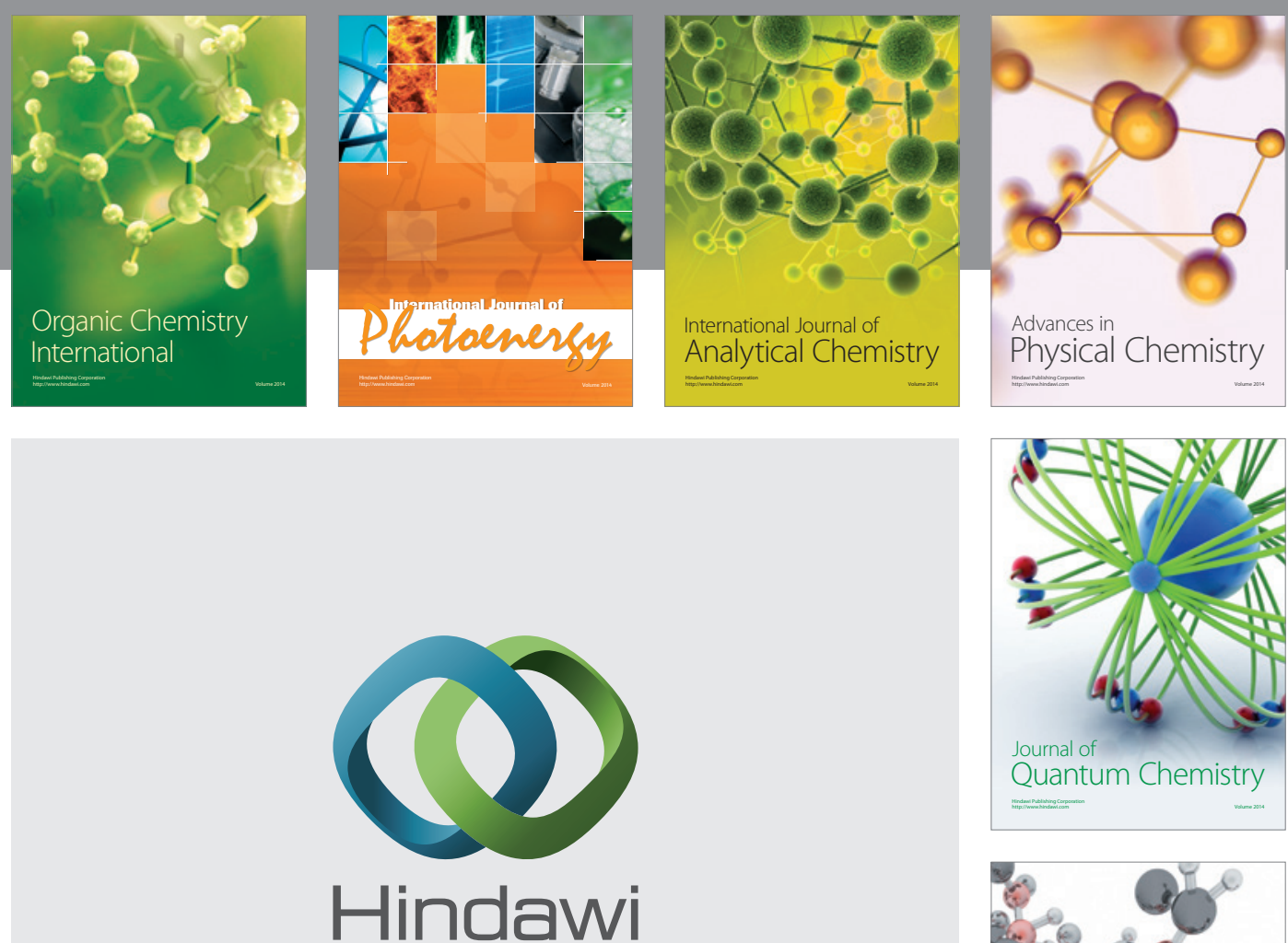

Submit your manuscripts at

http://www.hindawi.com

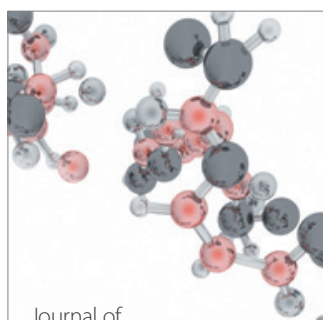

Analytical Methods

in Chemistry

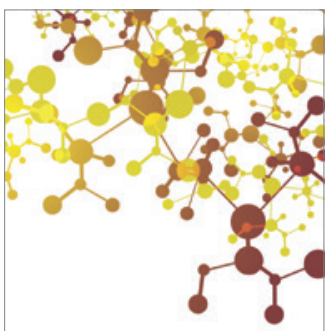

Journal of

Applied Chemistry

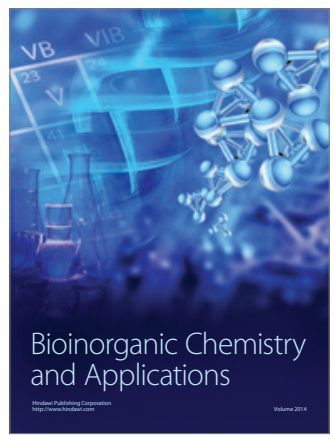

Inorganic Chemistry
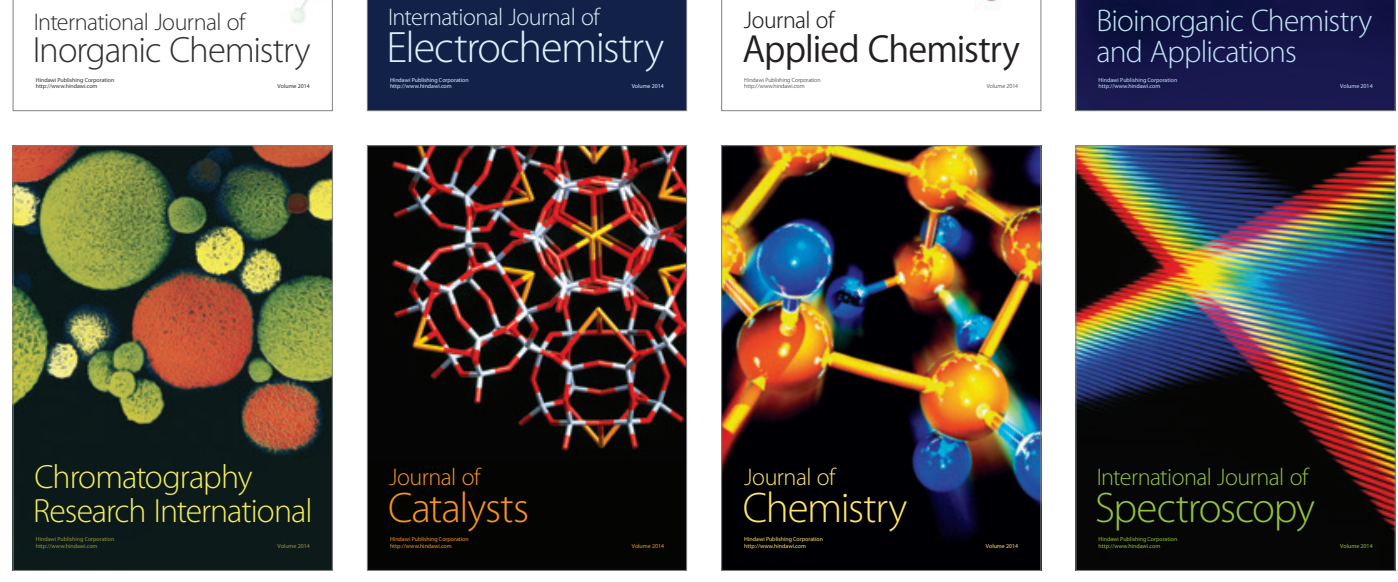